\title{
A CASE OF HEMATOMYELIA.*
}

\author{
By James Hendrie Lloyd, A.M., M.D., \\ NEUROLogist to THE PHILAdELPHIA hospital.
}

Cases of hematomyelia in which the lesion is exceedingly small and circumscribed, and in which the clinical phenomena are carefully studied and noted, are sufficiently rare and important to be worthy of a special detailed report. The following case was one of this type, as the patient was under observation during almost the whole short period between the accident and her death, and the lesion has been studied and illustrated with care. The case was one in which the only lesion was situated in the substance of the cord, for, although the accident had been one of great violence, no injury had been sustained by the vertebra or the membranes. It is thus representative of the pure type of hematomyelia-a rare type, whether due to trauma or to primary disease of the blood vessels. It has especial importance as throwing some light on the subject of spinal localization, and also as illustrating a class of cases in which the temptation is always great to invoke the aid of surgeryan aid which must necessarily always be in vain.

J. C., a colored woman, aged 53 years, in good health, without any personal history of alcoholism or syphilis, fell in the dark down a flight of stairs. She could not tell how she struck, or where she was injured, but she was immediately paralyzed in her arms, body, and legs. There was no loss of consciousness. The accident occurred on April 9, I899, and the patient was taken to a large general hospital, from which she was discharged unimproved in a few days for lack of accommodation. There was no history of her condition during these few days, except that she was paralyzed as above mentioned. On the I4th (five days after the accident) she was admitted into my wards at the Philadelphia Hospital.

On admission her condition was as follows:

Motion: There was complete paralysis in all the extremities. Plower was retained in the trapezius, sternocleidomastoid, and sternothyroid muscles, and in the diaphragm. The muscles of the chest were paralyzed.

* Read at the twenty-fifth annual meeting of the American Neurological Association, June I4 and I5, 1899. 
Sensation: Below a line indicated in the diagrams (Figs. I and II) all modes of sensation were absolutely lost.

Reflexes: There was a slight biceps and triceps jerk on the left side. Both knee-jerks were exaggerated. No ankleclonus. No plantar reflex. This preservation of the kneejerks is noteworthy.

Respiration was diaphragmatic and irregular. Inspirations were gasping, and not complete. There were no movements of the chest walls.

The bladder and rectum were paralyzed, and there was consequent incontinence of urine and feces.

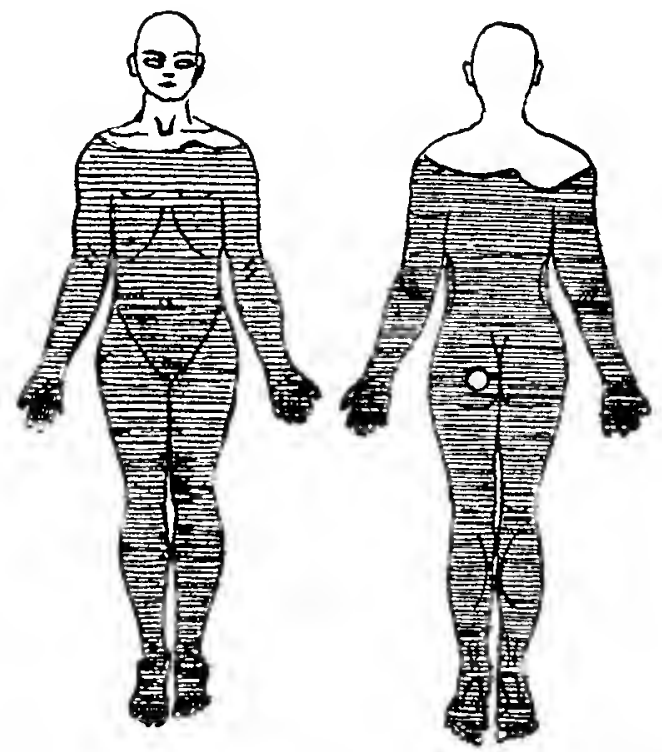

Figs. 1 and II. Hematomyelia. Total anesthesia below the neck. Bedsore on right buttock.

Cerebrum: The mind was clear, the patient responding promptly to questions. The tongue was protruded in a straight line.

Eyes: There was an old, probably congenital, double external strabismus. It was in no wise related to the patient's condition. It has been made the subject of special study by Dr. Oliver.

There was no spinal tenderness or deformity. There was no pain in the neck, and the movements in the neck, both active and passive, were good. 
In general, the patient's physical health was good. She was a large, robust woman, without any disease of the heart, lungs, kidneys, or abdominal organs.

April I 5. The patient said that she felt better, but her condition was practically the same as on admission. Careful tests were again made. The area of anesthesia had not increased. Retention of urine and feces was present during the night. The ciliary reflex from irritation of the skin of the neck was absent. An examination of the eyes was made by Dr. Oliver, who studied the congenital strabismus already
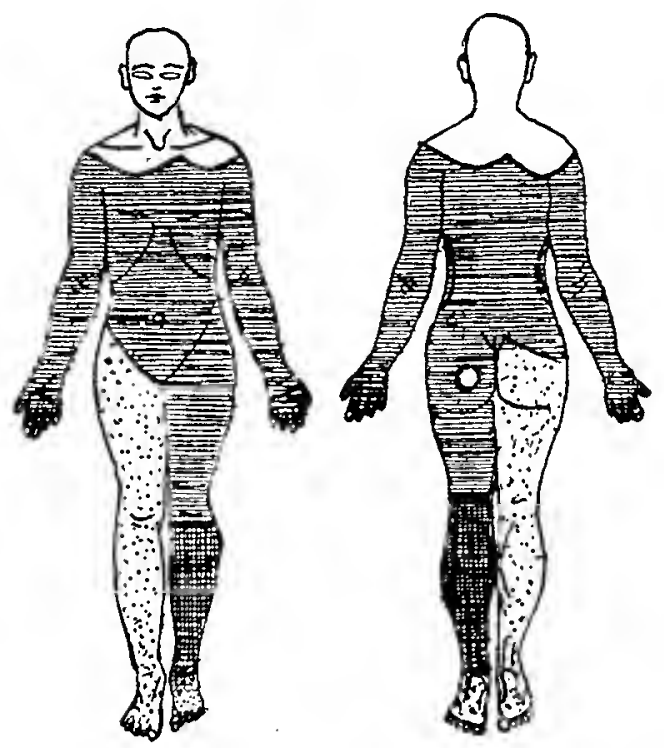

Figs. III and IV. Hematomyelia. Dotted area shows return of sense of pain. Crossed area shows return of sense of heat and cold.

noted. No affection of the eyes was observed by him that could be ascribed to the accident, except that there was no sympathetic mydriasis in either eye; but there was spastic myosis, although the pupils responded promptly to light and on accommodation.

April I6. About 4 P. M. the patient complained of pain in her knees. She breathed better. The bowels were moved by enema. Retention of urine continued. A bedsore on the left buttock, which had begun to form before the patient's admistion, had increased in size since the preceding day. 
Motion: Paralysis in all the extremities was still absolute. Pricking the leg caused it to be drawn up, but the patient had no control over it. Sensation: The sense of position had returned in the lower limbs. Pain sensation on pricking with a pin had returned in the right lower limb and left foot; also pain from pinching the muscles was noted in the same areas and in the left leg. The sense for heat and cold was noted about the right knee, but tactile anesthesia was still complete everywhere below the original boundary line. (See Figs. III
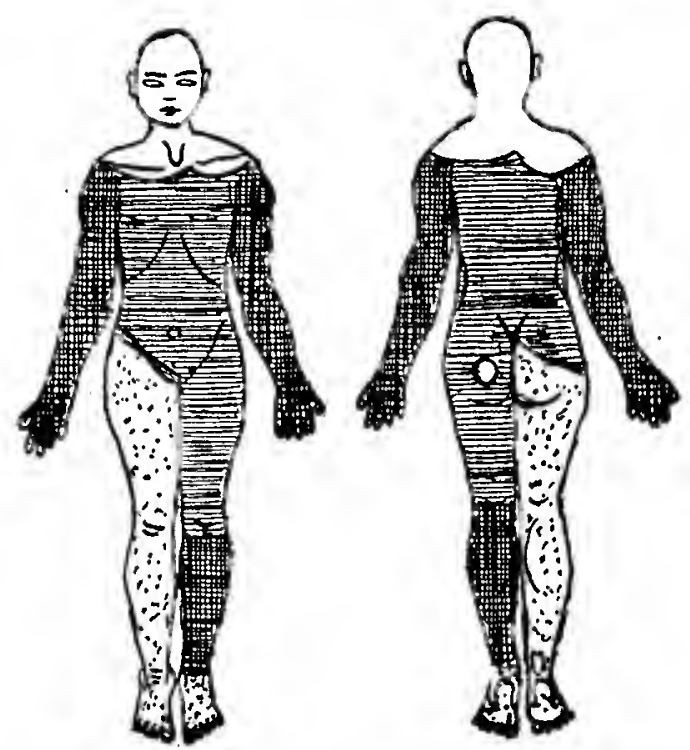

Figs. V and VI. Hematomyelia. Dotted area shows return of sense of pain. In crossed area sense of pain on pinching skin and muscles; also sense of heat and cold in limited spots.

and IV.) Later the pain sense returned in the upper limbs. (See Figs. V and VI.)

April I7. Breathing still better. Bedsore increasing superficially. Sense of position had returned partially in the upper limbs, and pain was caused by pinching the muscles in the arms. The only return of tactile sensibility was in the left foot, as noted yesterday, except that at times the patient could locate a pin prick in the left arm. No return of motion. The improvement in the breathing and the slight return of some of 
the modes of sensation caused the case to have a slightly better aspect on this day.

April I8. There was practically no change in the patient's condition on this day. In the evening Dr. La Place and Dr. Frazier, surgeons to the hospital, examined the spine, but they could not detect the presence of any fracture; hence, surgical interference was decided against.

April I9. The patient's condition was worse. The kneejerks were noted to be absent for the first time. Incontinence of urine continued. The breathing had again become diffcult. There was a slight bleeding from the right nostril, which, however, did not continue. The patient was somewhat stuporous, probably because of a rising temperature and deficient aeration of the blood. All sensation below tlie original line was again abolished, as on the patient's admission. There was now noticed for the first time moist skin above, and $d r y$ skin below this line. During the day the patient progressively failed. The temperature rose rapidly until it almost reached $106^{\circ}$. The lungs filled with moist râles. The breathing became more and more difficult from gradual paralysis of the diaphragm. Vomiting occurred at 6 P. M., and the patient died at 7 o'clock. She had survived the accident ten days. The notes of the case were taken by Dr. G. E. Pfahler, the resident physician.

Autopsy: Remarkably little evidence presented itself at the autopsy of severe injury to the structures of the neck. There were no wounds or ecchymoses in the soft structures. There was no deformity or swelling of the neck. The cervical vertebræ were uninjured; there was not the slightest dislocation or fracture, as determined by a searching examination. Within the spinal canal everything seemed normal at the first cursory view. The membranes presented nothing abnormal; they were not the seat of changes of any kind, such as would be caused by tearing or by inflammation. There were no meningeal hemorrhages. The cord itself at first, as viewed in situ, did not appear in any way changed. On closer inspection, however, even before it was taken out, it was seen to present a somewhat swollen appearance in about the midcervical region, and to be of an abnormal pallor at this point. The cord was removed without difficulty and without injury, as it was not perceptibly softened or adherent at the point of swelling. After its removal the underlying membranes and bones were carefully examined and found to be in every respect normal. On laying the cord open by making transverse sections through the affected portion, it was readily seen that it was the seat at this point of a small hematomyelia. To 
the naked eye the center of the cord seemed softened, and to contain quite a perceptible quantity of liquid blood or bloody fluid. This extravasation of blood appeared on gross inspection to occupy rather the central gray matter than the surrounding white substance, and to be rather larger than it proved to be eventually under the microscope. It was also seen later under the microscope that it was not so much the gray matter as the white that was involved. Its greater apparent extent in the fresh tissue was doubtless due to some degree of edema and engorgement. The general impression

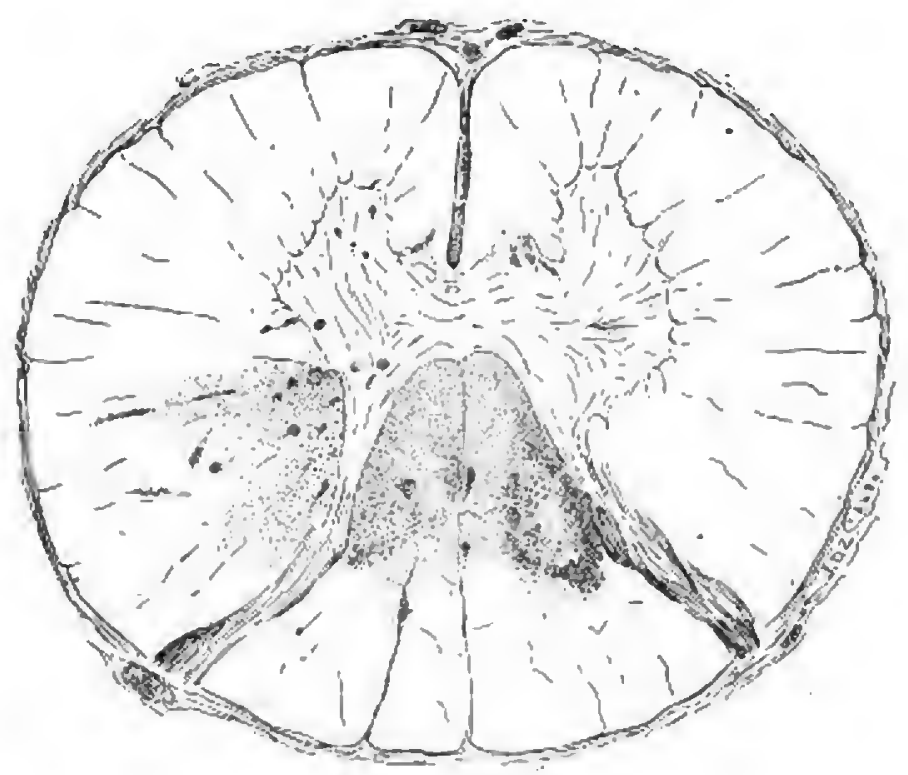

Fig. VII: Hematomyelia, Fourth cervical segment,

made upon all who saw the specimen in its fresh state was one of surprise that so little injury had been done, and that such a small lesion was capable of causing such speedy death. None of the other organs or tissues of the body presented any evidence of injury, or of any disease that is here noteworthy.

The miscroscopic sections of the cord have been kindly marle by Dr. Wm. G. Spiller, and present the following appearances:

The lesion is located entirely above the sixth cervical 
segment. The sixth segment presents nothing abnormal, except some rather doubtful appearances of degenerative changes about the periphery of the cord, and which are seen all through the higher segments which were the seat of the hemorrhage. These changes may have been caused by edema of the cord. There is no descending degeneration in the lateral columns at this point.

At the fifth cervical segment is seen the lowermost limits of the hemorrhage. These consist of three small areas located entirely in the posterior columns at their anterior limits. The larger of these is in one posterior column in direct contact with the gray matter; the other two, smaller in extent, are in the other columns, also in its anterior part. The surrounding white matter is here apparently normal, as the small hemorrhagic foci are sharply outlined. The gray matter is uninjured.

At the next level just above, and consequently involving the fourth cervical segment, the hemorrhage is seen in its greatest extent. It involves almost the whole of the anterior half of both posterior columns. It is symmetrically arranged, as represented in the diagram (Fig. VII.). Extravasated blood can be seen occupying a point in each column, and the white matter is extensively broken up. Dilated blood vessels are also present in and around the injured tissue. The gray matter is apparently quite exempt. The white matter, however, shows evidence at this level of injury in other regions, though not of hemorrhage. About the periphery and in the left lateral tract there is degenerated and swollen tissue, evidently the result of bruising and engorgement of the spinal medulla. The lateral tract is especially injured, and may, even contain some extravasated blood near the posterior horns. This posterior horn is thus involved possibly to some extent in the lesion, though its tissue does not seem to be deeply injured.

In the third cervical segment the lesion occupies almost the same limits as in the fourth, although it is evidently not quite so destructive. Other areas of degeneration are here more intense, especially the left lateral column, with the contiguous ascending cerebellar tract; also at the periphery of the anterior columns. In many scattered regions of the white matter in fact, at this level, although there is not deep degeneration, there is evidently such a condition as might result from bruising and swelling of the tissue; hence, it is evident that the cord was injured more extensively than is merely represented by the hemorrhage in the posterior columns.

At the second cervical segment the lesion is still quite extensive in the posterior columns, but this is apparently its uppermost limit, and it is not so extensive as below. The other 
changes in the white matter are about as at the lower levels, although not so intense. The lesion was not traced above this level. Its whole vertical extent may thus be said to be from the fifth upward to about the lower part of the second cervical segment. The lesion was thus in both its vertical and horizontal extent a comparatively limited lesion, consisting of a small hemorrhage in the anterior portions of the posterior columns, and of bruised and swollen tissue in these columns and also in some other comparatively limited areas of the white matter. With the thionin stain the multipolar cells in the anterior horns in this region show distinct chromatolysis. 'Many of them are much swollen and misshapen, and the chromophilic substance is broken up and in some instances entirely destroyed.

Analysis of the Symptoms: The clinical phenomena in this case are in the main clearly and logically related to the microscopic findings.

The motor symptoms indicate very clearly a lesion as high at lea'st as the third cervical segment, though not completely destructive of this segment. Thus the trapezius and the sternomastoid muscles, the motor nerve of which probably has some of its cells of origin in the third segment, were not paralyzed, but all the muscles of the body below them, except the diaphragm, were completely paralyzed. The exact spinal center for the phrenic nerve is a question of some uncertainty. Anatomists even differ as to the superficial origin of the nerve; thus Gray says that it arises from the third and fourth cervical nerves, while van Gehuchten says it arises from the fourth and from any anastomozing branch from the fifth. Mostclinicians in their diagrams locate the spinal origin in the fourth and fifth segments, but this localization is probably in most cases not indicative of very exact knowledge. The more exact tables founded upon the observations of Mills, Starr, Thorburn and others place the center for the phrenic nerve in the second, third and upper part of the fourth cervical segments. My case is confirmatory of this localization as a whole. The phrenic nerve was evidently involved, as shown by its embarrassed action, and yet its function was not totally abolished, as shown by the fact that the patient's life hung on it for ten days. Her death, however, was eventually brought about by progressive failure of this nerve - a termination which $I$ have seen in 
other cases of cervical injury, and which is due possibly to the gradual involvement of the motor cells and fibers of this nerve in a progressive degenerative action. In the case here reported, the third and fourth segments were extensively injured, but not totally so.

The sensory symptoms were indicative of a lesion as high at least as the third cervical segment. The fourth segment was undoubtedly invalidated, as it supplies sensation to the outer side of the arm, which in this case was anesthetic. The partial return of sensation for pain, heat and cold was an interesting phenomenon, and is probably to be explained by the fact that the central gray matter was not so much injured as the white. This is in accord with the view that the tracts for these modes of sensation pass through the gray matter, and then pass upwards through the anterolateral columns, which in this casse were the least involved. The only return of tactile sense was in one foot, which may be explained by the fact that the tactile fibers for the lower limbs pass in the neck by the posterior parts of Goll's columns, which in this case were not injured.

The state of the reflexes, especially the knee-jerks, was a point of interest. These were not abolished, but exaggerated. It is well known, since Bastian originally called attention to the fact, that in total transverse lesions, especially when accompanied with shock, as in traumatic cases, the knee-jerks are at first abolished. All the conditions in my case seemed to indicate that the knee-jerks should be abolished. The fact that they were preserved and even exaggerated, led me to the belief at the bedside that the patient did not have a total transverse lesion, although the motor and sensory paralysis was at first strongly indicative of such a lesion. This preservation of the reflexes may be associated in some way with the preservation of the gray matter.

The hyperidrosis above and anidrosis below the boundary line are worthy of special note. Irritation of the sympathetic system has been known to cause excessive sweating, and its paralysis the opposite condition. Unilateral hyperidrosis has been seen in cases of hemiplegia. I have reported a case of 
unilateral facial hyperidrosis in a case of hemiplegia. ${ }^{\mathbf{1}}$ In the present case the inference is that the sympathetic fibers were irritated above and paralyzed below the seat of lesion.

\section{DISCUSSION.}

Dr. Spiller said that Dr. Lloyd had sent him a portion of the spinal cord for examination. The cord had been cut through in several places, and it was therefore difficult to determine the segments. The eighth cervical segment has a very characteristic form, and is easily recognized, although this fact does not seem to be generally known. The anterior horns of this segment are very concave in their anterior portion. The necrotic areas in Dr. Lloyd's case were central, and involved the white matter more than the gray, and the nerve cells of the anterior horns in the injured portion of the cord showed distinct chromatolysis. Above the sixth cervical roots the segments could be determined only approximately.

Dr. Fisher said that Dr. Lloyd's paper had brought to his mind very clearly a patient who was under his observation last winter and recovered. A boy, while playing football, had his head driven forcibly down on his chest; he became unconscious and afterwards had paralysis from the neck down. One month afterwards he had complete inability to move the arms or legs and the sensory disturbance consisted in lowering, but not loss of all forms of sensations. The right arm and leg were more affected than the left, and showed considerable wasting. Gradually the condition changed, and he became more paralyzed on the left than the right side. The reflexes were very much exaggerated. He finally made a recovery with slight paresis involving the left lower extremity. Dr. Fisher came to the conclusion that the patient had some capillary hemorrhages in the spinal cord, probably in the lateral tracts. The case lasted a long time, and the symptoms were of as severe a character as would attend a graver lesion.

Dr. Patrick thought that these injuries to the cervical portion of the cord without fracture could not be very rare, because he had seen several of them, and in at least two cases had advised against operation, believing that the lesion was in the substance of the cord, perhaps principally in the gray matter, and the subsequent course of these cases seemed to justify that conclusion.

As regards the preservation of the knee-jerks in the case

${ }^{1}$ Twentieth Century Practice of Medicine, Vol. IX. In this article a number of literary references are given. 
reported by the President, Dr. Patnick thought that the preservation of sensation demonstrated that the section of the cord was not complete.

Dr. Onuf said he had had one case that was extremely instructive to him in regard to the sensory disturbances. It was a case of fracture of the vertebral column in the upper lumbar region, and there was absolute paraplegia. The lower limbs were completely paralyzed, but the sensation was preserved throughout in one extremity, although greatly diminished, and in the other extremity it was preserved in the thigh; but completely absent.in the foot and leg. In that case the preservation of sensation led him to make a good prognosis, and the patient made an almost complete recovery.

12. Ueber die Bedeutung der Zehen-Reflexe (Concerning the Meaning of the Toe-Reflex). Martin Cohn (Neurologisches Centralblatt, July I, I899, No. I3).

This investigation was undertaken to find out the importance of Babinsky's "Phenoméne des orteils," a reflex of the toes, caused by irritation of the sole of the foot. In normal cases a stimulation here is followed by flexion of the toe at the metatarsophalangeal joint. In injuries of the pyranidal tract, or when the same is made functionless by cerebral injury, an extension of the toe follows stimulation of the sole of the foot. Further, this phenomenon of extension is supposed to be one of the earliest symptoms of a lesion of the pyramidal tract, and it can be diagnosed from this symptom before any other signs appear. The following conclusions are noted by the author, as his results from the examination of normal and abnormal individuals: The extension movement of the toe is seldom found in persons with normal nervous systems. In infants as a result of the lack of myelin sheaths in the pyramidal tracts, according to Babinsky, the toe extension should always follow. In most cases, the author found this to be true; in other cases, however, no toe reflex was found at all. In abnormal cases the observations were made mostly on lesions in the pyramidal tracts. In two cases of amyotrophic lateral sclerosis, a clear extension of all toes was found. In two cases of spastic spinal paralysis the same result was observed. In another case of this disease a flexion of the second and fifth toes arid a weak extension of the first were noted, and in another case no reflex at all was found. In cases of fresh apoplectic paralysis, where according to Babinsky, this sign should be seen first, the author found no reflex at all. In two cases, an extension of the first toe was present while examination made a few days later showed no reflex at all. In two cases of cerebral tumor which had extended to the internal capsule, a definite extension movement was found on the side opposite to the tumor. In a case of total hysterical paralysis of one of the lower extremities, a toe extension movement was found on the paralyzed side, which was contrary to Babinsky's findings.

The author comes to the following conclusions: In the majority of all persons an irritation of the sole of the foot is followed by flexion of the toes. In lesions of the lateral tract of the spinal cord of an organic character, an extension reflex is to be observed. In no way, however, can this phenomenon be regarded as a certain pathognomic symptom for the recognition of such diseases. ScHwaB. 